\title{
Metallographic Characterization of Pyromet@ 718 Alloy Fasteners
}

\author{
George F. Vander Voort
}

Buehler Ltd., 41 Waukegan Road, Lake Bluff, IL 60044

\begin{abstract}
$\underline{\text { Abstract }}$
Alloy 718 is used in aerospace fasteners at two strength levels, 180 and $220 \mathrm{ksi}$ minimum tensile strength. The $180 \mathrm{ksi}$ minimum tensile strength bolts are solution treated and aged before cold forming the head (larger sizes require localized heating before heading). Thread rolling after aging produces the best fatigue life but service temperatures should be restricted to $900^{\circ} \mathrm{F}$ maximum. Operating temperatures to $1200^{\circ} \mathrm{F}$ can be tolerated if the threads are rolled before aging. The 220 ksi minimum tensile strength bolts are manufactured from solution annealed and cold drawn wire. Aging is performed after forming and operating temperatures are $\leq 900^{\circ} \mathrm{F}$. Plating may be performed to control clamping pressures or to prevent galvanic corrosion problems.

These variations in processing all influence the microstructure and can be detected in the finished product. This paper illustrates the microstructural differences due to strength level, heading technique and tread rolling before or after aging. Standard preparation procedures and etching techniques will be reviewed.

Metallographic examination of longitudinally-oriented fastener specimens produces a great deal of useful information about fastener quality. Indeed, metallography is an indispensable tool for evaluating fasteners. Examination can reveal the presence of cracks or other surface flaws which may or may not, be harmful depending upon their location and nature. Metallography also can detect features associated with the manufacturing process and characterize the strength of the fastener. All of this depends upon proper selection and application of metallographic procedures.
\end{abstract}

\section{$\underline{\text { Introduction }}$}

Metallographic specimen preparation of fasteners is relatively straightforward. Cutting of a longitudinally-oriented specimen can be rather challenging due to the difficulty in holding small fasteners while they are sliced parallel to the longitudinal axis. It is best to cut a short distance off the centerline and grind and polish to the centerline. Figure 1 shows a schematic of the usual sectioning approach. It is most common to examine the threaded section and the head region. A precision saw

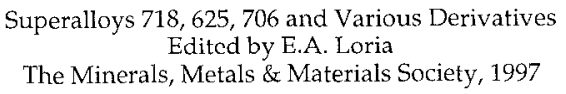




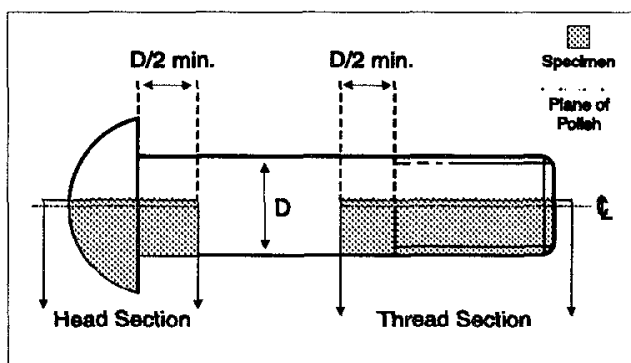

Figure 1 - Scctioning procedure for fasteners

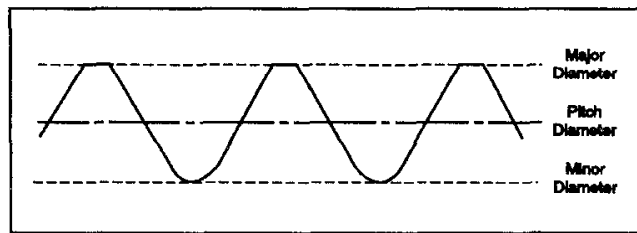

Figure 2 - Definitions of diameters.

with appropriate fixtures is very useful for such work. Smaller specimens are often mounted without sectioning. A portion of the head is cut off so that the fastener will lay flat on the ram. After mounting, grinding is continued until the centerline is reached. Examination of the threads often reveals abnormalities. Those below the pitch diameter (see Figure 2), especially those in the thread root, are most serious as they can act as sites for fatigue crack initiation. Head integrity is also important.

Good edge retention in mounting and polishing is required to assess the true structure at the surface of fasteners. While electroless nickel plating provides the ultimate degree of edge protection, it is usually not required. A modern, fully automated mounting press which cools the mount to near room temperature under pressure produces a tight mechanical mount with virtually no shrinkage gap between specimen and mount. If such gaps are present, edge rounding during polishing is promoted and bleed out after etching occurs. Elimination of the shrinkage gap makes the metallographer's job much easier.

A good mounting compound, properly cured, provides adequate edge retention. Compression mounting thermosetting epoxy powders, such as Epomet ${ }^{\circledR}$, provide excellent edge retention when used in an automated press. To reduce costs, Epomet can be placed in the bottom of the mold around the region of the plane of polish and a less expensive mounting compound, such as a phenolic, can be used to make up the rest of the mount. Alternatively, castable resins can be used for mounting. These do not require a mounting press and provide good adherence to the specimen. In this work, some of the specimens were split longitudinally, electroless nickel plated and mounted in epoxy so that the depth of grinding could be monitored. In some cases, the nickel pulled away from the fastener but edge retention was still excellent. The remaining specimens were compression mounted in Epomet.

Automatic polishing produces flatness and edge retention superior to manual "hand" polishing. The compression mounted specimens were mounted using an automated press which cooled the specimens to room temperature under pressure. Polishing was performed using automated equipment. Specimens mounted in liquid epoxy were electroless nickel plated before mounting. Polishing involved the use of napless cloths and polycrystalline diamond slurry compounds. Final polishing employed either an alumina suspension or colloidal silica on a vibratory polisher. Because of the use of the automatic mounting press, where the specimens are cooled back to room temperature under pressure, shrinkage gaps were not observed and no difficulties with bleed out of the etchant occurred, even when using an inverted microscope.

Metallographic preparation of nickel-based superalloys, such as Alloy 718, is not difficult but problems can arise if the procedures are not properly conducted. As always, sectioning is the most critical step as serious damage may be introduced if the wrong blade is employed or other problems occur. Excessive sectioning damage may be very difficult to remove in subsequent steps. A precision saw produces the least possible damage and makes execution of the subsequent steps easier. Steps must be performed to avoid introduction of excessive deformation. Because 718 may be used in either the annealed or the cold drawn condition, deformation of the austenite matrix due to preparation may be confused for processing deformation. Cold work can crack the carbides in 718 


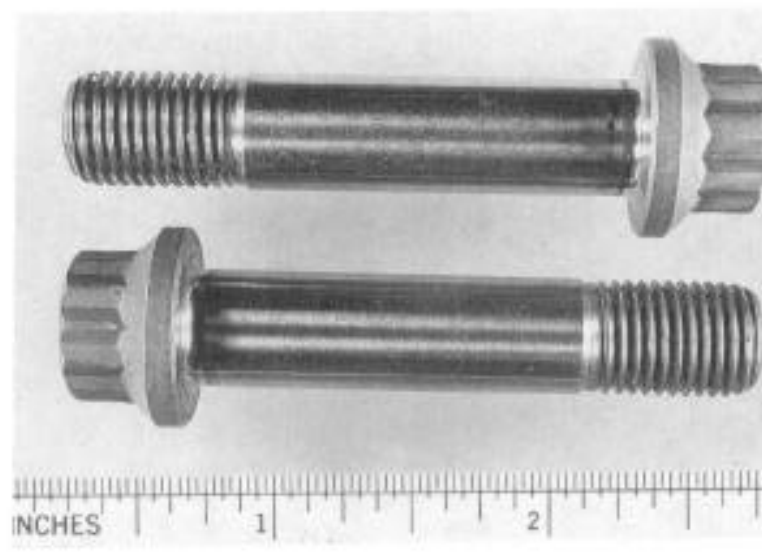

Figure 3 - EWB tension bolts.

but impropoer sectioning and preparation techniques can also crack carbides. One must be able to differentiate between carbides cracked by the processing (cold drawing) and carbides cracked by the preparation practice. Good practices will prevent the latter so that, if cracked carbides are observed, the metallographer can be certain that they were in the alloy from drawing. Metallographic techniques for superalloys are covered in references 1 and 2. These references review much of the metallographic preparation literature on superalloys.

Etching of alloy 718 can be performed using a variety of etchants but $\mathrm{I}$ prefer to use glyceregia $(15 \mathrm{~mL} \mathrm{HCl}, 10 \mathrm{~mL}$ glycerol, $\left.5 \mathrm{~mL} \mathrm{HNO}_{3}\right)$ or acetic glyceria $\left(15 \mathrm{~mL} \mathrm{HCl}, 10 \mathrm{~mL}\right.$ acetic acid, $\left.5 \mathrm{~mL} \mathrm{HNO}_{3}\right)$. These must be mixed fresh and are used by swabbing. Their life is limited to no more than about $15-30$ minutes. From a convenience point, waterless Kalling's reagent is often used as it can be stocked and has a long life. Alloy 625 (discussed in this conference) is more difficult to etch. The best etch is mixed acids, $15 \mathrm{~mL} \mathrm{HCl}, 10 \mathrm{~mL}$ acetic acid, $10 \mathrm{~mL} \mathrm{HNO}_{3}$, which is used by swabbing. These, and other etchants, are discussed in (1 and 2). Glyceregia was used for the work shown here.

\section{$\underline{\text { Results }}$}

Figure 3 shows two Alloy 718 Ni-based superalloy [2] EWB tension bolts which measured $63 \mathrm{~mm}$ long with an $11.1 \mathrm{~mm}$ shank diameter and a $13.9 \mathrm{~mm}$ diameter head $(18.9 \mathrm{~mm}$ diameter at the wrench flats). The shank had a hardness of 521 to $533 \mathrm{HV}$. At the base of the socket hole in the head, the hardness was $497 \mathrm{HV}$ while slightly below this area it was $526 \mathrm{HV}$. On the wrench flats, and at the junction between the wrench flats and the head, the hardness was 560-563 HV. In the teeth, the hardness was $620 \mathrm{HV}$ while at the tooth root it was $660 \mathrm{HV}$. This suggested that the teeth were cold rolled.

Figure 4 shows the microstructure in the shank body revealing delta phase and a fine grained

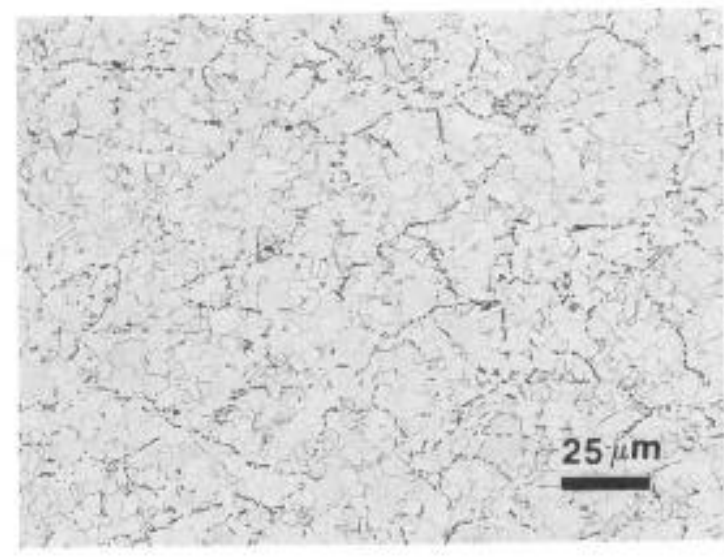

Figure 4 - A coarse delta distribution within a deformed austenite matrix in the tension bolt.

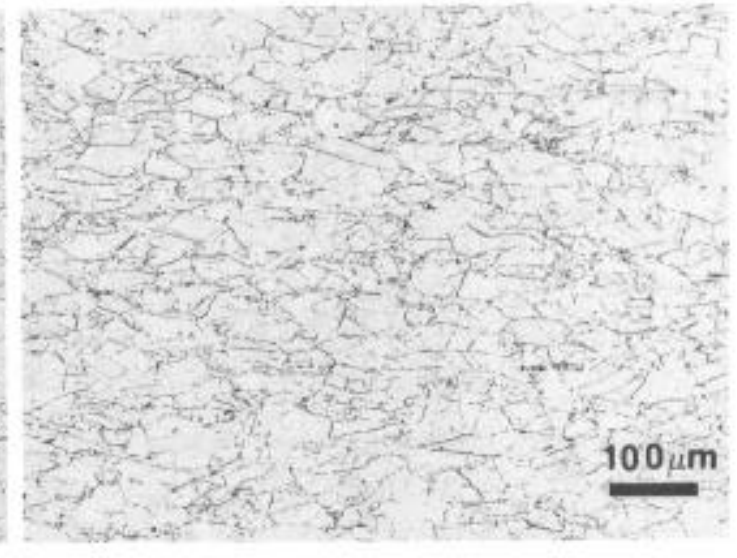

Figure 5 - Highly deformed head region (some of the delta was dissolved) in the tension bolt. 


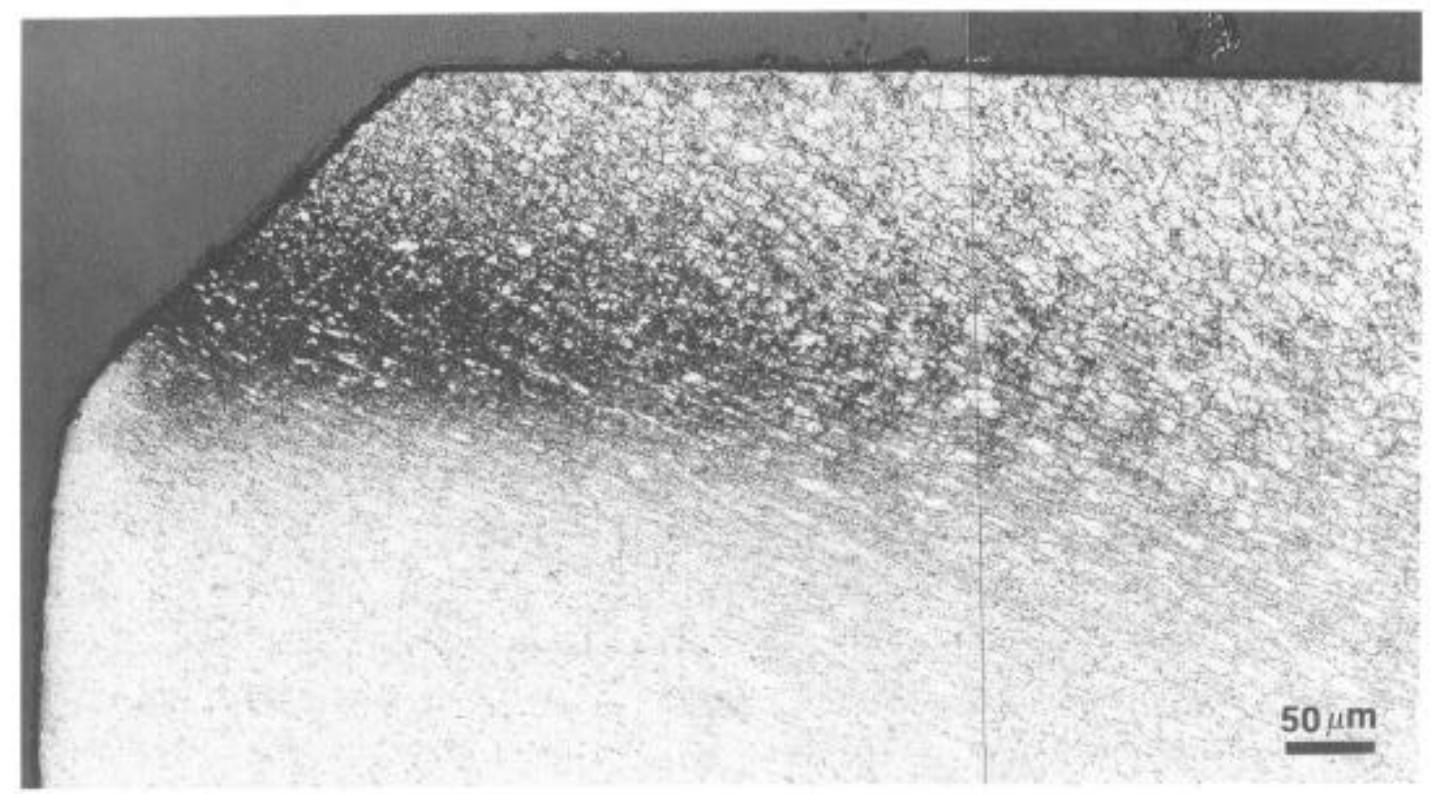

Figure 6 - Heavy deformation on the head side of the wrench flat of the tension bolt.

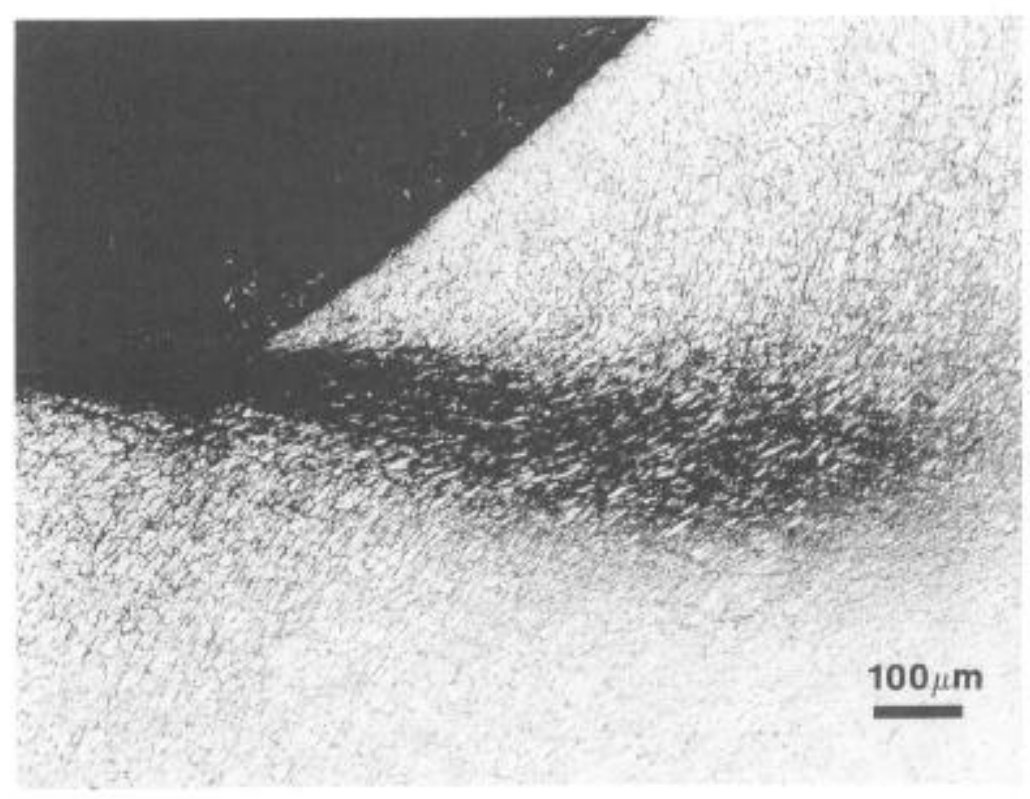

Figure 7 - Adiabatic shear band at the junction between the head and the wrench flat of the tension bolt.

austenitic grain structure. There is evidence of prior cold work in the structure. The network of delta phase is a bit coarse (and deformed by drawing), which indicates a relatively high hot rolling finishing temperature (at the last pass). After hot rolling, the wire was given a low temperature, $1775^{\circ} \mathrm{F}\left(967^{\circ} \mathrm{C}\right)$, solution anneal which did not dissolve the delta phase network. The wire was cold drawn to the desired size. Figure 5 shows the structure in the center of the head revealing a 


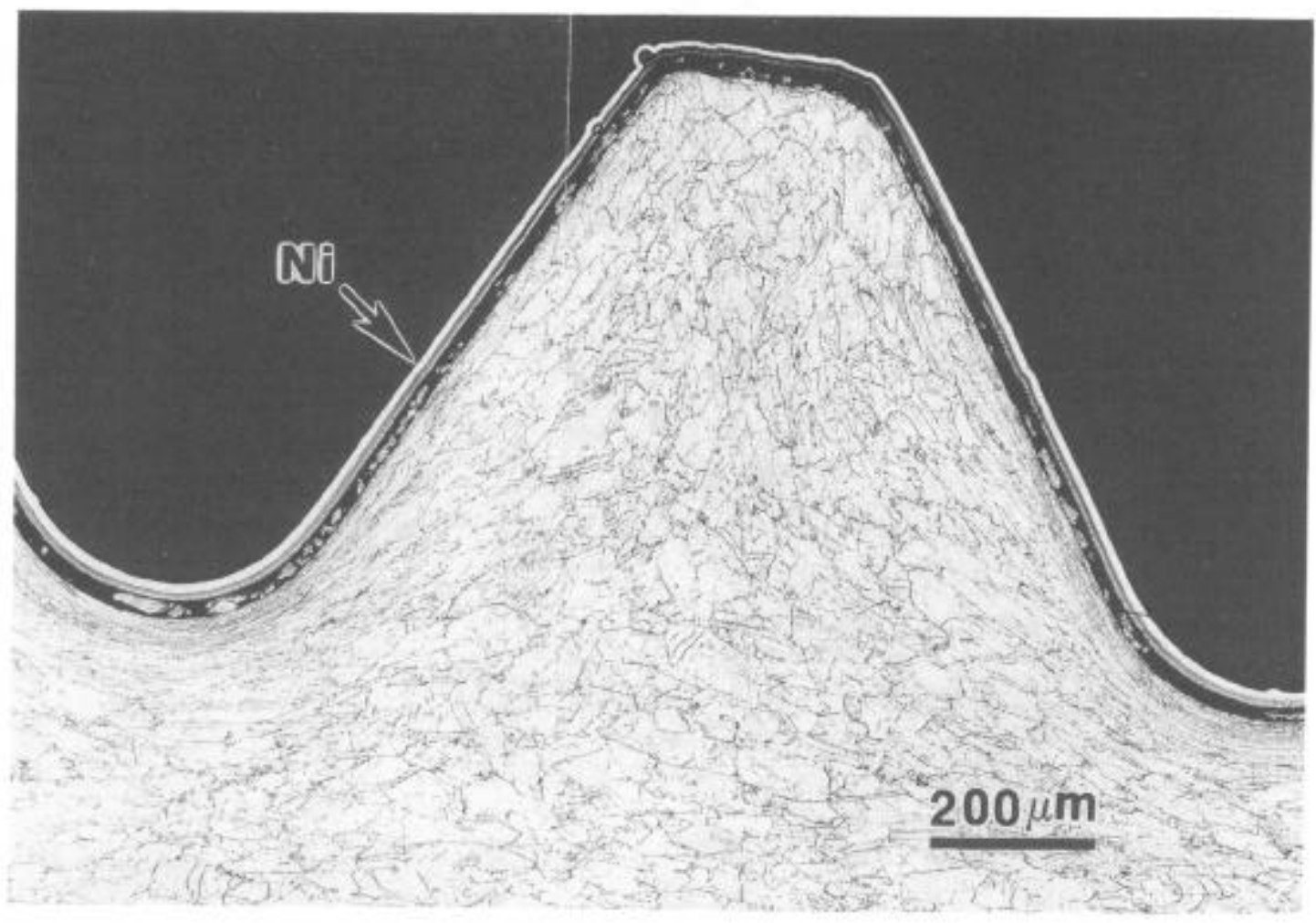

Figure 8 - Montage showing the deformation along the surface of the cold rolled teeth in the tension bolt. Note the nickel plating which has pulled away from the tooth.

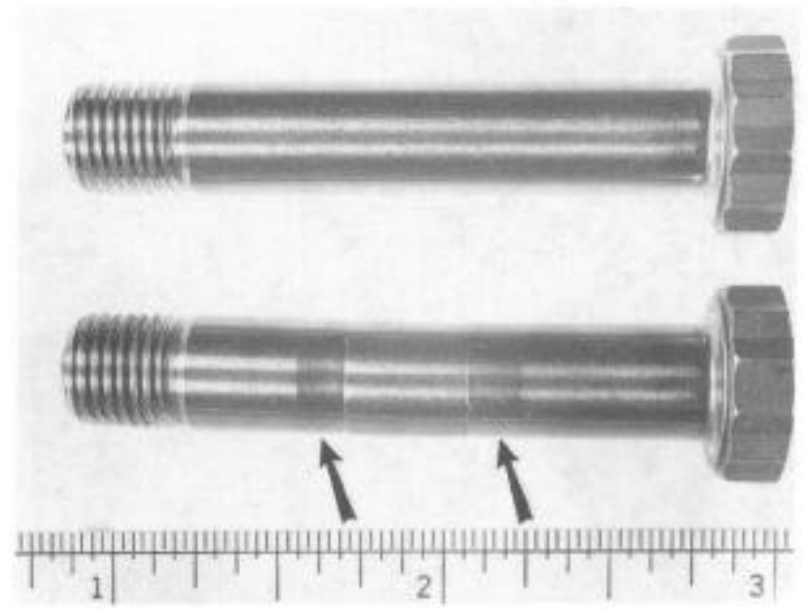

Figure 9 - EWB shear bolts (arrows - shear test).

deformed grain structure. In contrast, Figure 6 shows the structure at the OD of the wrench flats revealing a band of heavy deformation and Figure 7 shows heavy deformation (adiabatic shear band) at the junction of the wrench flat and the head. This structure is rather controversial as some consider it a rejectable condition for certain applications. The area to be formed into the head was locally heated by induction and hot forged. Finally, Figure 8 shows the microstructure of a tooth. Note the highly deformed grains within the tooth and along the tooth surface, particularly at the tooth root. It appears that the teeth were formed by cold rolling after aging.

Figure 9 shows EWB shear bolts made from Alloy 718, one (bottom) was tested in shear (note marks and slight bend of the shank). These bolts were about $57 \mathrm{~mm}$ long with a $9.5 \mathrm{~mm}$ diameter shank and a $15.7 \mathrm{~mm}$ diameter head. The wire appeared to have been purchased in the cold drawn condition. The shank hardness was $568 \mathrm{HV}$ and the head hardness was slightly lower.

The rod stock for the shear bolt was hot rolled using a lower finishing temperature resulting in a finer austenite size. The rod was solution annealed at the normal temperature, $1950^{\circ} \mathrm{F}\left(1066^{\circ} \mathrm{C}\right)$, resulting in a finer delta dispersion. Then, the wire was cold drawn to size. 
The head of the 718 shear bolt was hot forged after localized induction heating. Areas in the head that received little hot work revealed a fine recrystallized grain structure while areas of intense deformation, such as along the top surface towards the head periphery, Figure 10 , reveal intense flow. Under the head, in the fillet region, there are adiabatic shear bands, as shown in Figure 11. Since the starting rod was cold drawn heavily (to get a higher strength), it is impossible to avoid these shear bands. While some consider these to be harmful defects, they are impossible to avoid under such conditions.

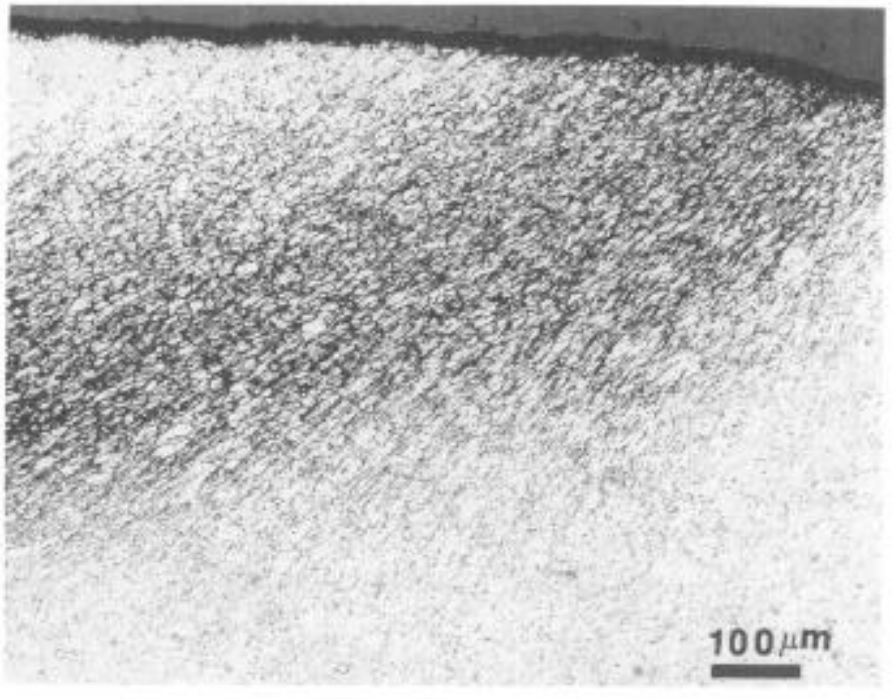

Figure 10 - Heavy deformation at the top of the shear bolt.

The teeth microstructure in the shear bolt was extremely fine

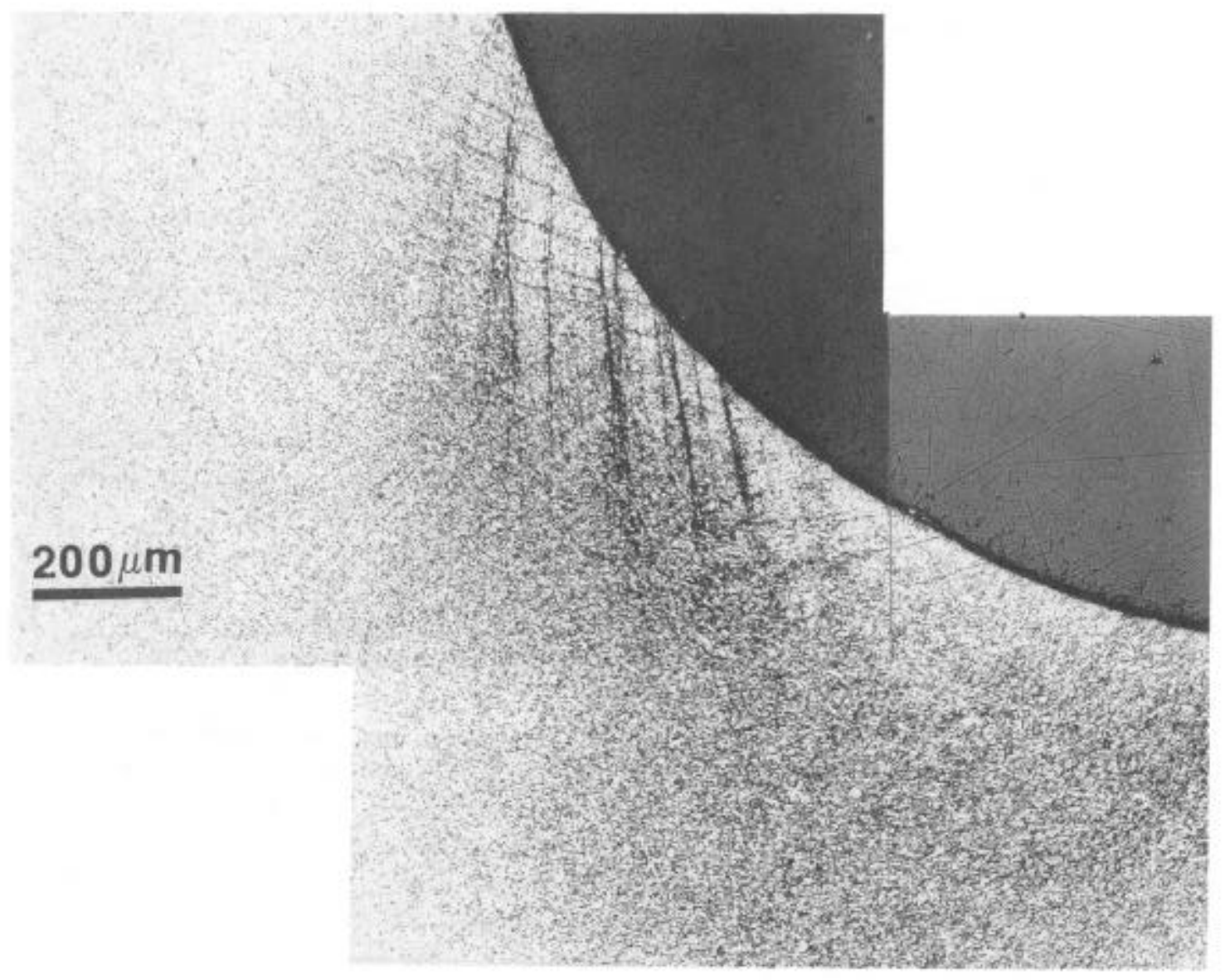

Figure 11 - Montage showing the adiabatic shear bands in the head/shank fillet of the shear bolt. 


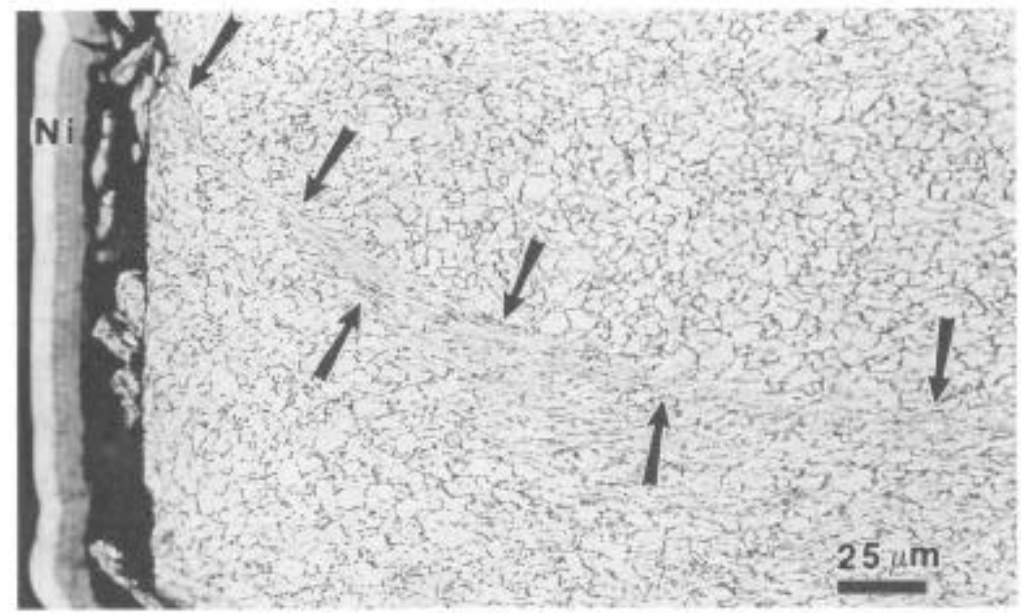

Figure 12 - Lap-like defect at the crest of a tooth in the shear bolt. Note the nickel plating which has pulled away from the tooth.

and exhibited substantial deformation. Figure 12 shows an example of one of the teeth which was electroless nickel plated (note that the plating has pulled away from the tooth during mounting). The tooth crest is on the left. Note the metal flow pattern which appears to be a lap.

Figure 13 shows four $220 \mathrm{ksi} 718$ tension bolts with diameters of $7.9,14.3,19.1$ and 34.9 $\mathrm{mm}$. These bolts were split longitudinally, off center, using an Oscillimet ${ }^{\mathrm{TM}}$ abrasive saw and mounted in $50.8 \mathrm{~mm}$ diameter mounts of Epomet using an automated mounting press (Simplimet(B) 2000). They were polished using the Phoenix 4000 semi-automatic polisher. The first step used a woven stainless steel "cloth", Ultra-PadTM, and $45-\mu \mathrm{m}$ polycrystalline diamond slurry, Metadi@ Supreme, for 5 minutes using $2.75 \mathrm{~kg}$ load per specimen (head at $150 \mathrm{rpm}$, rotating in the opposite direction of the base, rotating at $300 \mathrm{rpm}$ ). The next step used a heavy polyester cloth, Ultra-Plan ${ }^{\mathrm{TM}}$, with $9-\mu \mathrm{m}$ polycrystalline diamond slurry for 4 minutes (other conditions same as above). The third step used a napless chemotextile pad, Texmet ${ }^{3} 2000$, and 3 - $\mu \mathrm{m}$ polycrystalline diamond slurry for 3

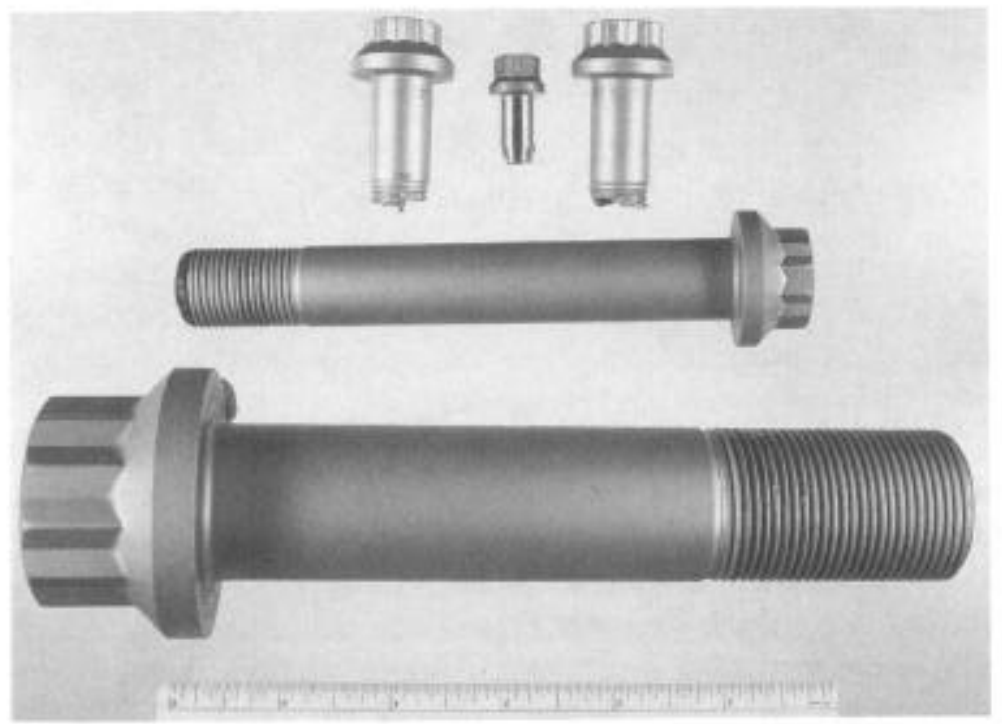

Figure 13 - $220 \mathrm{ksi}$ UTS 718 tension bolts with diameters of 7.9, 14.3, 19.1 and $34.9 \mathrm{~mm}$. 

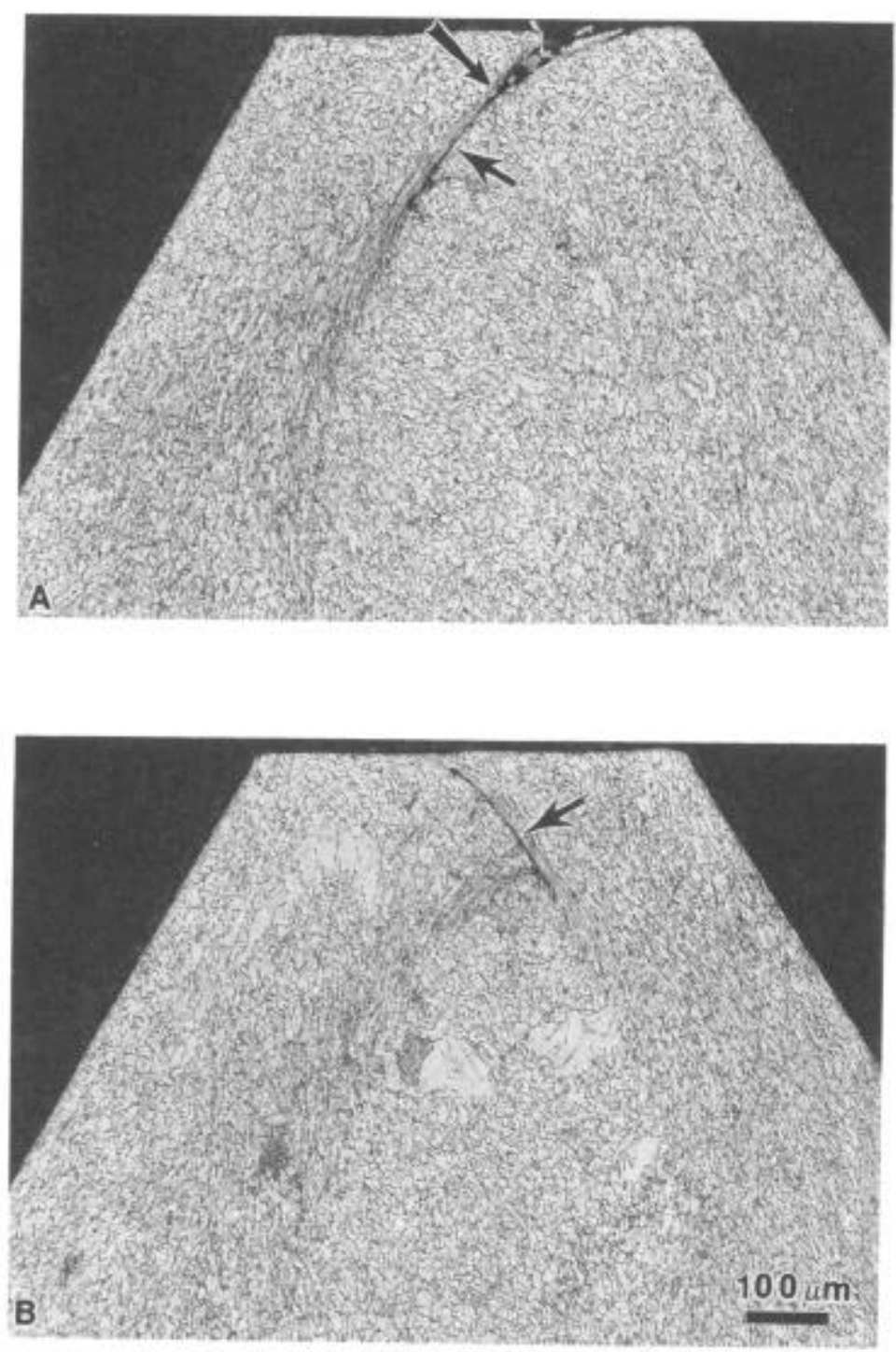

Figure $14 \mathrm{a}$ and $\mathrm{b}$ - Lap at the crest (a) and (b), note arrows, and non-recrystallized grains in (b) in $34.9 \mathrm{~mm}$ diameter bolt. minutes (other conditions still the same). The fourth, and final, step used a synthetic chemically resistant napless polishing pad, Chemomet@ I, and a $0.05-\mu \mathrm{m}$ alumina suspension, Masterprep $^{\mathrm{TM}}$, for 1 minute (head rotating in the same direction as the base, which was at $150 \mathrm{rpm}$, other conditions the same). This produced surfaces free of damage from sectioning, grinding and polishing and free of scratches.

In these bolts, the starting stock was cold drawn with a reduction of $20-25 \%$.

This produces cracked carbides.

The head region is heated by induction and hot headed, which recrystallizes the structure. This is most evident in the head areas that receive little deformation.

The regions that experience considerable metal flow show intense deformation. There was intense deformation at the edge of the wrench flat surface while a fine grained, equiaxed austenite, with very little delta, was observed in the center of the head of the $7.9 \mathrm{~mm}$ diameter bolt. In comparison, the center of the head of the $19.1 \mathrm{~mm}$ diameter fastener had a much coarser grain structure due to grain growth. The shank grain structure was also coarser but the delta was not dissolved, the grains were not equiaxed, but elongated, and the carbides were cracked. Hot forming of the head apparently heals the cracked carbides (which are much smaller in size) by flowing matrix into the prior voids.

The teeth in these bolts were generally well formed and no defects were observed below the pitch line. The $34.9 \mathrm{~mm}$ diameter bolt, however, did reveal crest defects, Figure $14 \mathrm{a}$ and $\mathrm{b}$. Note the large unrecrystallized grains present in the tooth in Fig. 14b. Unrecrystallized grains, some quite large and elongated, were observed along the top corner of the head, Figure $15 \mathrm{a}$, in the wrench flat region, Figure 15b, and in the shank under the threads. In the center of the head, the grains were recrystallized and equiaxed with most of the delta put into solution. Some nitride stringers were observed in the head region. An example is given in Figure 16. Cracked carbides were observed in the cold worked regions in the shank, Figure 17, but not in the hot formed head. 

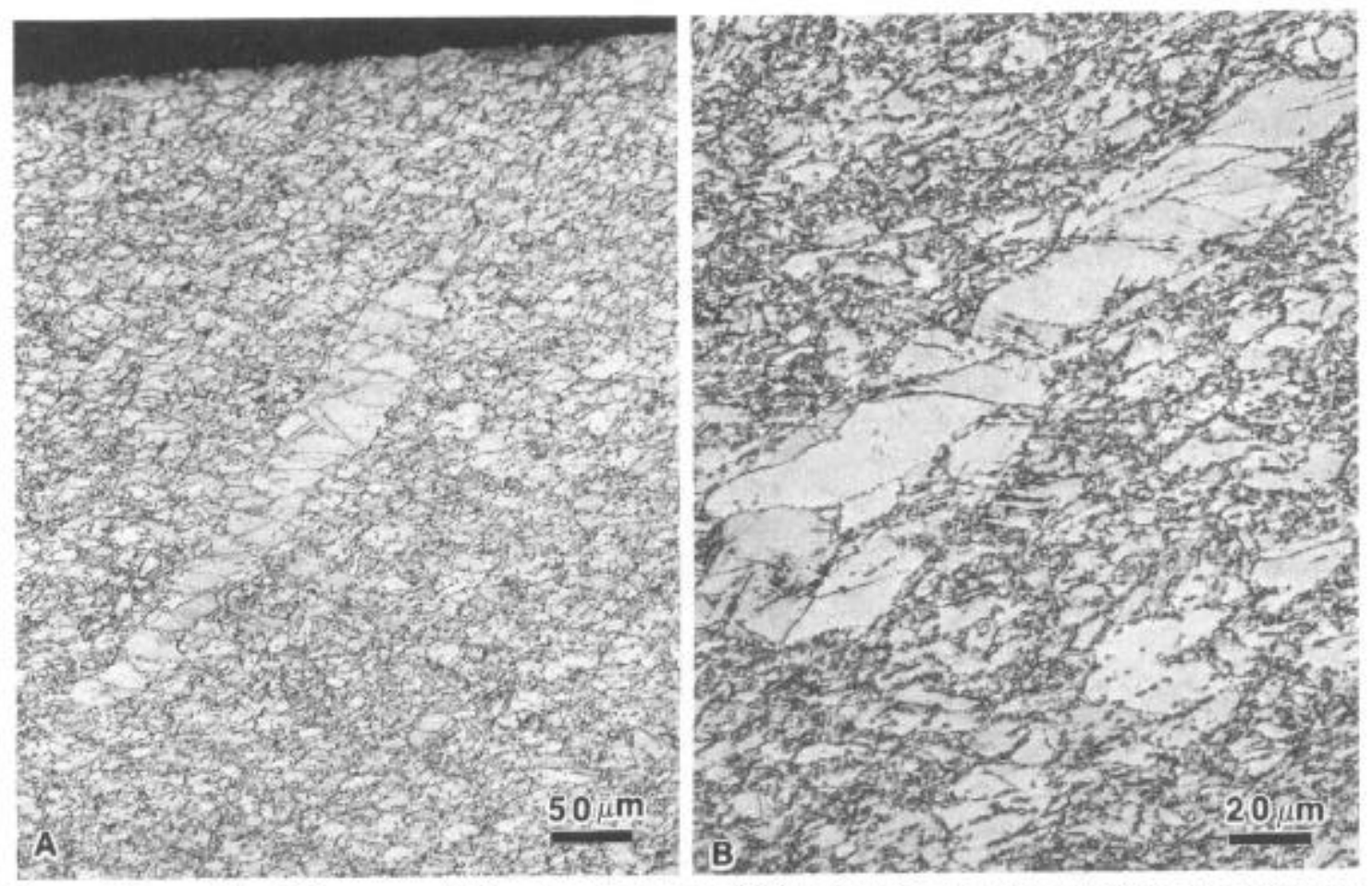

Figure $15 \mathrm{a}$ and $\mathrm{b}$ - Non-recrystallized grains in the $34.9 \mathrm{~mm}$ diameter bolt at (a) the top surface of the head; and, at (b) the corner of the wrench flat.

\section{Conclusions}

Metallography is a powerful tool for evaluating the quality of fasteners, For the fastener manufacturer, metallographic examination is a necessity for evaluating the affects of the manufacturing process steps on bolt integrity and strength. The metallographic procedures must be selected based upon the problems that may be encountered with the grade of material. These steps must be properly executed so that the true structure can be revealed at any desired location. The best etchant must be chosen and etch time should be controlled so that the optimum contrast is obtained when viewed with the light microscope. Interpretation requires a knowledge of the material in question, its heat treatment and relevant specifications. While certain imperfections are obvious causes for rejection, others may be more difficult to categorize.

Alloy 718 fasteners can be prepared using standard metallographic procedures but the use of modern consumables and equipment makes the work easier and more reliable. Cracked carbides can be expected in areas that were cold drawn large amounts. Subsequent hot heading heals the voids. Intense deformation and shear bands can be found in the heavily worked regions and in the areas that experienced lower temperatures. Delta phase is generally present in the starting stock to inhibit grain growth. Hot heading solutions much of the delta but grain growth is usually not extensive as the pieces are not at heat for long. Thread roots will exhibit cold work, which is beneficial to fatigue life, if these were cold rolled after aging. 

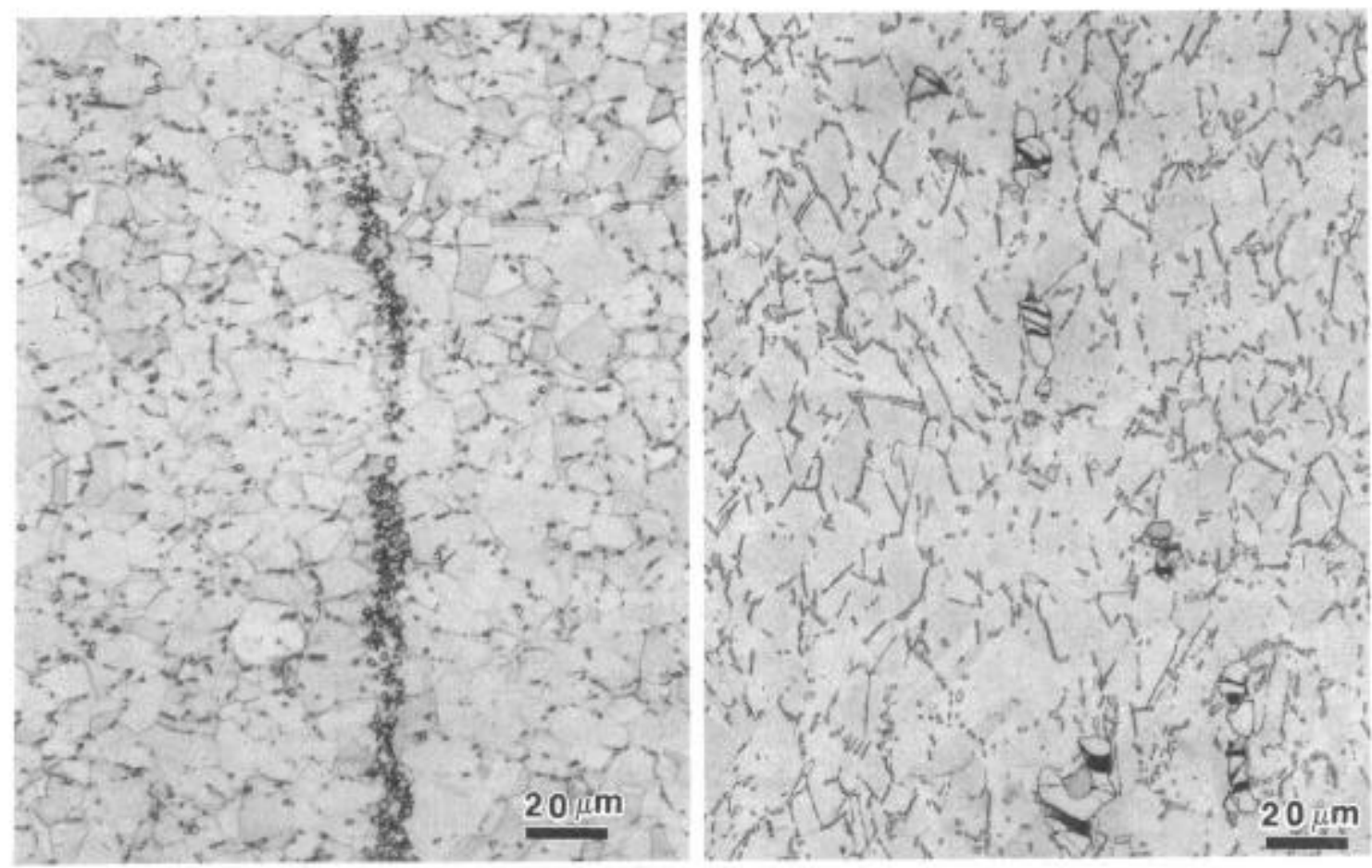

Figures 16 (left) and 17 (right) - Nitride stringers were observed in the head of the $34.9 \mathrm{~mm}$ bolt (left) and cracked carbides in the shank (right). The longitudinal axis is vertical in the photos.

\section{References}

1. G.F. Vander Voort, Metallography: Principles and Practice, McGraw-Hill Book Co., New York, 1984.

2. G.F. Vander Voort and H.M. James, "Wrought Heat Resisting Alloys," Metals Handbook, 9th Edition, Volume 9, Metallography and Microstructures, American Society for Metals, Metals Park, Ohio, 1985, pp. 305-329.

\section{Trademarks}

Pyromet is a registered trademark of Carpenter Technology Corporation, Reading, Pennsylvania. Oscillimet, Ultra-Pad, Ultra-Plan and Masterprep are trademarks and Epomet, Simplimet, Metadi, Texmet and Chemomet are registered trademarks of Buehler Ltd., Lake Bluff, Illinois. 